Territory. Uranium oxide will be available at a competitive price, but the Government is prepared to stock-pile the output for a number of years should this be necessary. Production figures were the highest so far recorded. Mary Kathleen Uranium, Ltd., is expected to complete its contract with the United Kingdom Atomic Energy Authority by the end of 1963. The Radium Hill mine and its associated chemical treatment plant at Port Pirie were closed during December 1961. Exploration for uranium is now virtually confined to existing producers, and the Commonwealth's offer to pay rewards for the discovery of uranium in Australia and Territories has been withdrawn, with the final reward instalment during the year of $£ 14,800$ in respect of the Eva deposit at Pandamus Creek, N.T.

Visitors to the Commission and to the Research Establishment during the year under review included Sir William Cook, Sir John Cockroft, Air Chief Marshall Sir Claude Pelly, of the United Kingdom Atomic Energy Authority; Dr. G. A. Robb of the New Zealand Atomic Energy Committee; Dr. P. C. Abersold of the United States Atomic Energy Commission and Congressmen J. E. van Zandt and O. E. Teague; Dr. G. A. Siwabessy of the Indonesian Institute of Atomic Energy; Dr. J. P. Hugo of the South African A.tomic Energy Board; and Mr. F. R. Herrington and Mr. C. H. Hetherington of Atomic Energy of Canada, Ltd. Training for fellows of the International Atomic Energy Agency at the Research Establishment was continued and a voluntary contribution was made to the general fund of the Agency to assist in its technical assistance programme. The Commission published a large number of photographs, leaflets and booklets to satisfy the lively public interest in atomic energy, in addition to its more scientific and informative quarterly journal Atomic Energy. Several major exhibitions were presented, including one at the Sydney Trade Fair, and at the Sydney Town Hall during the convention of the Australian Welding Institute, and on nuclear power in Perth during May and in Adelaide during June.

The research programme at Lucas Heights is supplemented by university research contracts. All the universities in Australia together with the Commission are members of the Australian Institute of Nuclear Science and Engineering, and each university has research projects supported by Institute grants. Approximately fifty research projects involving co-operation with the Research Establishment were being sponsored during the period covered by the annual report. Details are given in a separate section and in an appendix to the report.

\title{
LONG-DISTANCE RADIO COMMUNICATION AT HIGH-FREQUENCIES
}

$\mathrm{P}$ ENDING the application of satellite relays to intercontinental communications, the world's long-distance radio services have been developed on high-frequencies or short waves, which are reflected from the ionosphere in their transmission around the Earth. A survey of the present state of technique in this field and of modern trends in equipment was conducted by the Electronics Division of the Institution of Electrical Engineers at a convention on "High-frequency Communication" on March 25-27*.

This convention was attended by some 290 participants, including a number of overseas visitors, and more than 50 papers were presented at the eight technical sessions. The texts of all contributions and formal papers included in the programme were issued in a preprinted booklet, and many of the papers were marked as having been accepted for publication in a future issue of the Proceedings of the Institution.

On the first day, two sessions were held dealing respectively with the propagation of high-frequency waves by way of the ionosphere, and with the design of aerial systems for the most efficient communication over distances both below and above $1,000 \mathrm{~km}$. On the succeeding days, the papers read and discussed related to the various systems used in modern radio-telegraph communication and to the special technical problems associated with the development of both fixed and mobile equipment. While much ingenuity has gone into the advance design of signalling techniques and the automatic correction of any errors which occur in transmission, the limiting factor in most long-distanco radio links lies in the mode of trans. mission of high-frequency waves by way of the ionosphere.

For many years now, using a network of ionospheric observatories, conditions in the ionosphere have been investigated by the well-known technique of sounding at vertical incidence. The results of these soundings, which in most cases are made day and night throughout the year, are exchanged on an international basis, and co-ordinated at certain recognized institutions. From these records of past measurements, forecasts are made of the highfrequency radio transmission conditions likely to prevail

* Institution of Electrical Engineers: Electronics Division. Convention on H.F. Communication March 25-27, 1963-Proceedings. Pp. 444. (London: Institution of Electrical Engineers: 1983 . in the future in various parts of the world. Such forecasts have in general been made for periods of from one to six months ahead; but, as the operation of the observatory network extended over ono or two sunspot cycles, each of about eleven-year periods, it has become possible to produce charts for the epochs of maximum and minimum solar activity. Interpolation between these epochs was assisted by the continuing measurements at a number of key stations throughout the world. While such arrangements are satisfactory for the long-term planning of communication circuits, the performance of these have always been subject to erratic, and in many cases unexpected, variations in the ionospheric conditions, and these have prevented the use of many radio circuits to their full capacity.

With the view of overcoming this limitation, an investigation has been in progress in some countries of methods of sounding the ionosphere under oblique incidence conditions, and, so far as is practicable, over the path of the actual communication circuit in question. Such 'oblique ionosphere sounding' as it is termed, is effected by using a transmitter emitting pulses on a series of increasing frequencies, with synchronizing arrangements for maintaining the receiver at the remote station in tune with the same series of frequencies. A paper describing this technique under the title "Oblique Sounding and H.F. Communications" by R. D. Egan and D. S. Pratt was presented at the convention. In the arrangement described, the sounder transmitter is set to begin sending pulses on a predetermined frequency at a particular time within $1 \mathrm{msec}$ after each pulse, the frequency is increased in a series of rapid steps so as to cover the entire high. frequency band of $2-32 \mathrm{Mc} / \mathrm{sec}$ in a fow soconds. At the receiver, the frequency is kept in step with that of the transmitter by electronic digital control after a starting signal initiates the sequence of frequency stepping. By this means oblique incidence ionograms are produced from which the upper and lower limits of frequency which can be propagated over the chosen path are readily obtained. The authors of the aforementioned paper also describe an extension of their research to the direct control of a communication circuit on a 24-h basis, by locating a sounder transmitter at the communication sending site near Anchorage, Alaska, and a sounder 
receiver at the communication receiving station near San Francisco, California.

Following the publication of the technical paper referred to here, The Times of June 19 gave some details of an ionosonde developed by E.M.I.-Cossor Electronics Ltd., Halifax, Nova Scotia; and demonstrated recently to Commonwealth representatives, the Services and other organizations intorested in long-distance radio communication. The equipment was shown in operation between a sending station in Nova Scotia and the Post Office radio-receiving station at Cooling Marshes, near Rochester,
Kent. At the sender, the frequency was swopt in a series of 128 steps from 1.8 to $28 \cdot 8 \mathrm{Mc} / \mathrm{s}$, and the receiver was synchronized with the aid of standard time-signals. The received signals were displayed on a cathode-ray tube which, with the changing conditions in the ionosphere, indicated the most suitable frequency at any moment for transmission over this trans-Atlantic path. In addition to the direct assistance given to high-frequency communication, the ionosonde can be used for the scientific investigation of ionospheric conditions.

R. L. SMITH-Rose

\title{
NEW MATERIALS TESTING LABORATORY FOR THE CEMENT AND CONCRETE ASSOCIATION
}

$I^{N}$ $\mathrm{N}$ a recent issue of the Magazine of Concrete Research (15, No. 43; March 1963), J. D. McIntosh gives an interesting account of the imposing new laboratory erected for the Cement and Concrete Association at its research station at Woxham Springs, Stoke Poges, Slough, Bucks. The interest lies not so much in the fact that this is a much desired extension to the existing facilities at Wexham Springs, designed to re-house various departments hitherto operating in temporary accommodation, but in what may be termed the very 'tight' specification to which the building had to conform. The primary function of the new laboratory is research on the engineering properties of concrete and its constituent materials, including soil-cement; all necessary facilities for studying these problems and for structural model testing had to be provided and somewhat stringent measures had to bo taken to ensure that working conditions, for example, high degree of temperature control and correct relative humidity, in many of the rooms, were satisfied. In this, air-conditioning of much of the building plays an important part; it influenced the siting, planning and method of construction of this laboratory. "Particular problems included reducing nuisance from the dust and noise of many operations, preventing the spreading of shock and vibration to the rest of the structure, planning a convenient flow pattern for routine operations while allowing adequate versatility for other techniques, and filtering 'live' cement from liquid waste. Although all the desirable refinements were not included at the time of eroction, provision was made, where possible, for them to be incorporated later"
Thus the design of a materials-testing laboratory calls for solution of many problems not encountered in ordinary building, or at least much less critically. Every eventuality seems to have been foreseen in the present instance. Although ideally premises in which such fundamental research can be carried out should provide controlled conditions which can be taken for granted, any breakdown in vital equipment should be limited in its effect by appropriate planning in advance. While on one hand the layout should be designed in such a way that frequently recurrent operations can be reduced to a fool-proof routine, the building of this nature must be readily adaptable to now processes or testing procedures. It certainly seems from Mr. McIntosh's detailed description. of this new laboratory, coupled with the site-plan, floor plans and other illustrations in his paper, that the latest Wexham Springs project will eventually, if it has not already done so, fulfil the ideals which its sponsors and its architect had in mind. It certainly provides a most intriguing prototype for other buildings destined for similar purposes in the future and as it is intended that visitors will be encouraged to "see something of the laboratories without hindrance to the work in hand" (by provision of large windows between corridors and rooms and special circulation spaces), there will be no obstacle to architects and others concerned with design of special buildings for scientific work obtaining first-hand visible and highly valuable information on basic requirements.

H. B. Milner

\section{ISOSTATIC RECOVERY IN SCOTLAND}

\author{
BY D. F. W. BADEN-POWELL \\ Department of Geology and Mineralogy, University of Oxford
}

GOME years ago evidence was published for a corre$\checkmark$ spondence in height and fossil content of some British raised beaches and those of the Mediterranean area ${ }^{1,2}$. If the correlations based on that work are correct, there is obviously a contradiction with the theory that northern Britain has been rising during the Holocene as a result of isostatic recovery or that recent extensive tilting has occurred in England. In other words, if some British raised beaches which were originally horizontal are now tilted, their heights cannot be used as evidence of correlation with the Mediterrancan area. Recent work on the Pleistocene marine fauna of the Nar Valley Clay of western Norfolk and on an almost identical fauna from other parts of Britain has shed new light on recent crustal movements as a whole, and some widely held opinions on this subject must now be changed.

Jamieson ${ }^{3}$ seems to have been one of the first geologists to suggest that many Scottish raised beaches might be due to local uplift, and W. B. Wright ${ }^{4}$ later enlarged
Jamieson's ideas by assuming that most of the Scottish beds are late- or post-glacial and are not represented in the south of England, whereas the English fossil beaches were supposed to be much more ancient. This idea has bcen accepted so generally that it is often forgotten that it was challenged by Deperet ${ }^{5,6}$, who considered that some of the marine beds in the north can be correlated with those of southern England, and that it is not nocessary to invoke any form of crustal movement to explain their distribution. Another nearly related problem is that of the supposed recent tilting of the southern parts of Britain. The original levelling of England and Wales was done by the Ordnance Survey during $1840-60$, and when the re-levelling was carried out betwoen 1912 and 1921 , a discrepancy of nearly $2 \mathrm{ft}$. was found near Harwich and the Essex coast, as though there had been a submergence here since the original survey. Sir Charles Close ${ }^{7}$ thought this discrepancy was due to changes in sea-level caused by local meteorological effects and not to vertical crustal 